\title{
Picturing Efficiency: Precisionism, Scientific Management, and the Effacement of Labor
}

Sharon L. Corwin

Colby College, sharoncorwin@gmail.com

Follow this and additional works at: https://digitalcommons.colby.edu/faculty_scholarship

Part of the American Art and Architecture Commons, American Studies Commons, and the Photography Commons

\section{Recommended Citation}

Corwin, Sharon L., "Picturing Efficiency: Precisionism, Scientific Management, and the Effacement of Labor" (2003). Faculty Scholarship. 63.

https://digitalcommons.colby.edu/faculty_scholarship/63

This Article is brought to you for free and open access by Digital Commons @ Colby. It has been accepted for inclusion in Faculty Scholarship by an authorized administrator of Digital Commons @ Colby. 


\title{
Picturing Efficiency: Precisionism, Scientific Management, and the Effacement of Labor
}

\begin{abstract}
In i 9 i i, Frederick Winslow Taylor published The Principles of Scientific Management. It is not surprising that Taylor would open his primer on the rationalization of labor by invoking President Theodore Roosevelt's plea for greater "national efficiency." The threat of waste and inefficiency was a growing American concern in the early decades of the twentieth century. The solution, according to Taylor, was a system of scientific management that employed precise time measurements and complex equations in an effort to achieve "maximum efficiency" from the worker. ${ }^{2}$ Toward this goal, workers were surveyed and timed by engineers with stopwatches in order to determine the most efficient manner of carrying out a task. These methods were essential to a system that functioned by closely observing the workforce, simplifying labor to repetitive tasks, and dictating significantly higher workloads. Taylorism told workers not only what to do but exactly how to do it: each movement, each minute, was strictly managed.

The time-motion studies conducted by the efficiency experts Frank and Lillian Gilbreth expanded upon Taylor's methods, initially so as to improve the efficiency of workers in the bricklaying trade. ${ }^{3}$ Ultimately, they were interested in finding what they called "the One Best Way" - that is, the optimal way of performing a task with the smallest degree of wasted motion. The Gilbreths concluded that by instructing workers on the "right" way to pick up and place a brick, significant time and physical effort could be saved, and the overall efficiency of the job could be greatly increased. ${ }^{4}$ Frank Gilbreth claimed that their system was able to reduce the number of motions required in bricklaying from eighteen to four and a half. ${ }^{5}$ (The question of what constitutes half a motion seemed to matter less than the "scientific" valence
\end{abstract}

\footnotetext{
ABSTRACT In the early decades of the twentieth century, the pursuit of efficiency came to dominate instances of industrial and artistic production: the engineering consultants Frank and Lillian Gilbreth attempted to visualize a language of minimal waste, while Precisionist art achieved its own aesthetic of efficiency. This essay examines the Precisionist project alongside the discourses of the rationalized factory and suggests a relationship between the formal economy of Precisionism and the rhetoric of scientific management. For Precisionist art and the Gilbreths' time-motion studies, the representation of efficiency ultimately entailed the elision of artist and worker as producers of labor. / Representations 84 (C) 2004 The Regents of the University of California. Is s N 0734-6018 pages 139-65. All rights reserved. Send requests for permission to reprint to Rights and Permissions, University of California Press, Journals Division, 2000 Center St., Ste. 303, Berkeley, CA 94704-1223.
} 
that such a figure might suggest.) This was a claim in its own right. What made the Gilbreths' project revolutionary, however, was that it introduced the camera into scientific management. Whereas Taylor recorded his experiments with only a stopwatch, the Gilbreths incorporated photographic technologies into the field of efficiency engineering. Through the use of motion picture and stereo cameras, they recorded workers' motions in an attempt to identify and eliminate what they saw as unnecessary and wasteful movements.

What, then, does efficiency - or, for that matter, waste-look like in the Gilbreths' experiments? ${ }^{6}$ How was efficiency reified and given visual form? And how did the aesthetics of efficiency, standardization, simplification, and economy enter into dialogue with other contemporaneous forms of visual representation, in particular, the formal project of Precisionist art? In the discussion that follows, I explore the relationship between scientific management and paradigms of visual representation - specifically, the clean lines, standardized geometries, and simplified facture of the Precisionist canvas. I am interested in not only the social effects but also the visual effects of Taylorism and efficiency engineering. In other words, I examine how representational practice responded to the social changes brought by the rationalization of the factory. Precisionist art, specifically the work of Charles Sheeler, presents one such response. As one critic wrote in 1926, the qualities of "directness" and "incision" that characterize Sheeler's art are "equally evident in the work of our engineers and scientists." It is striking that at the moment Precisionism emerged, artists and engineers were understood to be using the same visual vocabulary. The pursuit of efficiency came to dominate artistic and industrial production, and both were affected profoundly by the intersection between scientific, economic, and aesthetic concerns.

"Precisionism" is a name that art historians coined in the 1940s and retrospectively applied to the art of a group of American modernists - including Georgia O'Keeffe, Stefan Hirsch, Louis Lozowick, Morton Schamberg, and Sheeler - who worked in a specific pictorial mode during the interwar years. ${ }^{8}$ Characterized by a "precise" style of linear forms and almost imperceptible brushwork, Precisionism registers formally what had become a cultural obsession with efficiency, and it can be seen as giving form to its own particular version of an aesthetic of efficiency. Significantly, it was through the effacement of labor - whether it be the body of the worker or the traces of artistic labor - that both the Gilbreths' time-motion studies and Precisionist painting could achieve a representation of efficiency and a seeming excision of waste. Yet at times, such efforts to produce a vision of efficiency were anything but efficient. The pursuit of a new language of minimal effort, quantification, and simplification often took on an obsessive and ultimately counterfactual quality; for in both art and the factory, looking efficient did not always mean being efficient. This paradoxical condition haunts both the Gilbreths' experiments and Precisionist art. 
By the first decade of the twentieth century, the cult of efficiency had moved beyond laboratories and factories to infiltrate American culture at large, and its rhetoric often took on moral and national overtones. Theodore Roosevelt proclaimed in 1909 that "the three great requirements of national life" were "to be fearless, to be just, and to be efficient." As historian Samuel Harber puts it, "Efficient and good came closer to meaning the same thing in these years than in any other period of history." ${ }^{\prime 10}$ Nor did its importance soon wane. At the height of the Depression, the social theorists Stuart Chase and George Soule attacked capitalism not for its oppressiveness but rather for its wastefulness and inefficiency. ${ }^{11}$ And in 1937, Franklin D. Roosevelt called for a government that could battle "against ineffectiveness, against waste, against inefficiency." 12

The efficiency craze was woven deep into the cultural fabric and found applications outside the obvious realms of business and labor. ${ }^{13}$ To gauge the depth of this new obsession, consider its incursions into language: neither spelling nor writing were safe. Melville C. Dewey, founder of the Dewey decimal system, organized a simplified spelling movement that attempted to eradicate what it saw as extraneous letters used in the spelling of English words. ${ }^{14}$ (Dewey even "simplified" the spelling of his own name, preferring the more "efficient" appellation Melvil Dui, thereby saving all of four letters. $)^{15}$ Frank Gilbreth participated in this movement by advocating the replacement of "old, obsolete, inferior or even ridiculous standards" with "spellings standardized in accordance with the One Best Way." ${ }^{16}$ He went even further by extending his own notions of efficiency to the written word. For Gilbreth, it was not only spelling that stood to be simplified, but script as well. What was needed, he proposed, was a new and more efficient written alphabet:

The most offhand analysis of our written alphabet shows that it is full of absolutely useless strokes, all of which require what are really wasted motions. Consider the single example of the first stroke of the first letter of each word. Here is a motion that can be eliminated wholly. ${ }^{17}$

In this "age of waste elimination," as the Gilbreths called it, no activity was beyond the reach of efficiency engineering. ${ }^{18}$

The Gilbreths' time-motion studies were similarly concerned with the elimination of "wasted motions." " These experiments, drawing on Etienne-Jules Marey's innovations in chronophotography, were carried out by placing small lights on the hands of workers. ${ }^{20}$ The workers were then instructed to repeat a task while their movements, which registered photographically as lines of light, were recorded through the time exposure of the camera (fig. 1). These photographic motion studies - or "cyclegraphs," as they were called - were intended to provide visual data that could be used to establish the most efficient way of conducting a task. ${ }^{21}$ From these diagnostic studies, three-dimensional wire models were constructed by fol- 


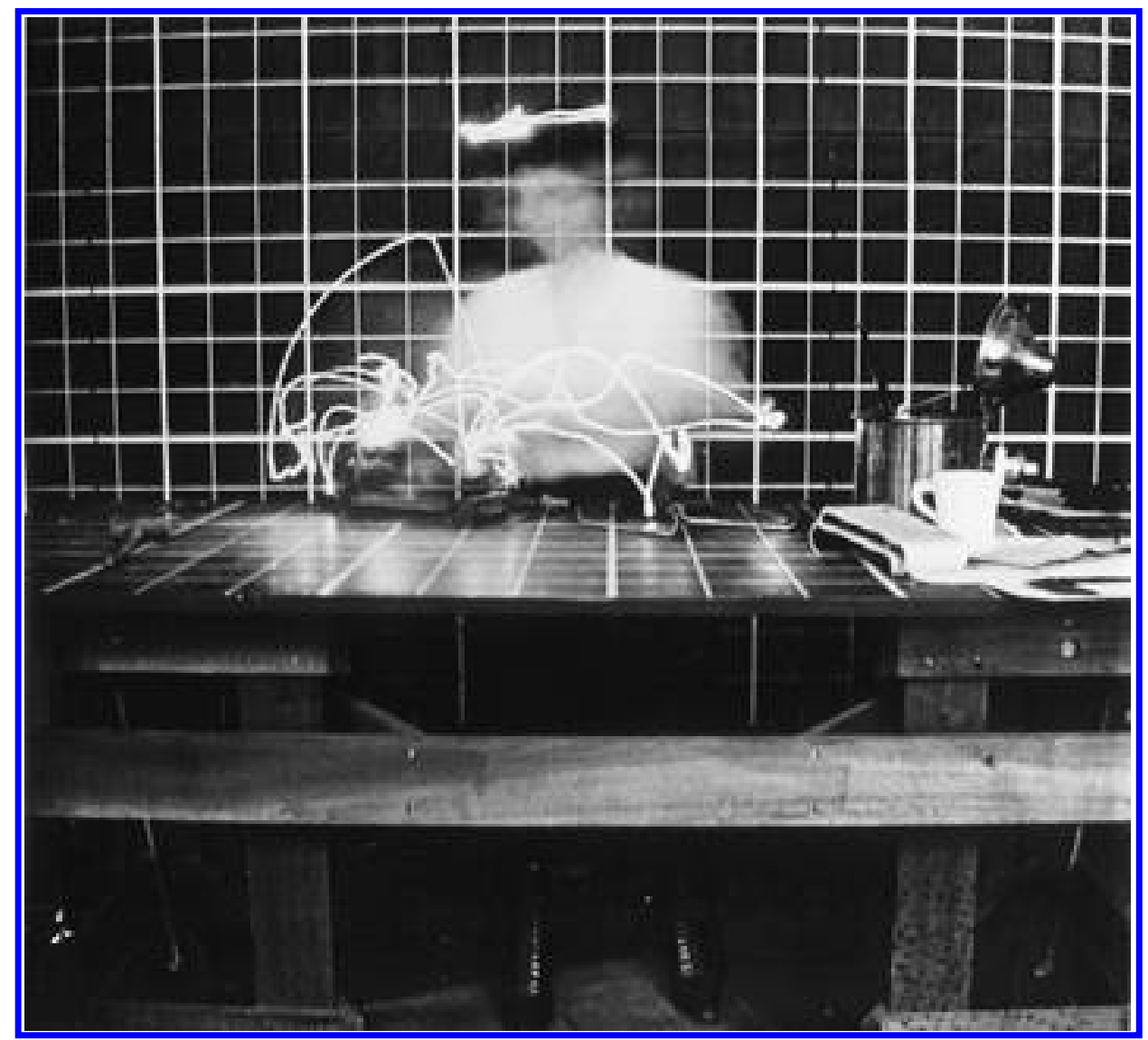

FIGURE 1. Frank and Lillian Gilbreth, untitled cyclegraph (light assembly study), n.d. Gilbreth Collection, National Museum of American History (NMAH), Smithsonian Institution, Washington, D.C.

lowing the path of light patterns in the photographs (fig. 2). By visualizing what the Gilbreths called the "paths of least waste," these strange sculptural models were meant to instruct the workforce on the most efficient way of carrying out a task. ${ }^{22}$ The idea was that workers could imitate the path of motion illustrated by the cursive line of the wire model in order to increase their own efficiency. ${ }^{23}$ The Gilbreths also argued that efficiency engineers could benefit from the "educative value" of the models. As one such specialist testified, "I consider them of the same value to the motion study man as the model of an engine or a mechanical device to an engineer." 24

It is important to stress just how odd these models really are. ${ }^{25}$ With their sinuous wires set against painted grids (a sign of their "scientific" import?), the models verge upon futuristic fantasy — one made all the more ominous by the stark lighting 
FIGURE 2. Frank and Lillian Gilbreth, untitled motion models, c. 1913-14. Gilbreth Collection, NMAH.
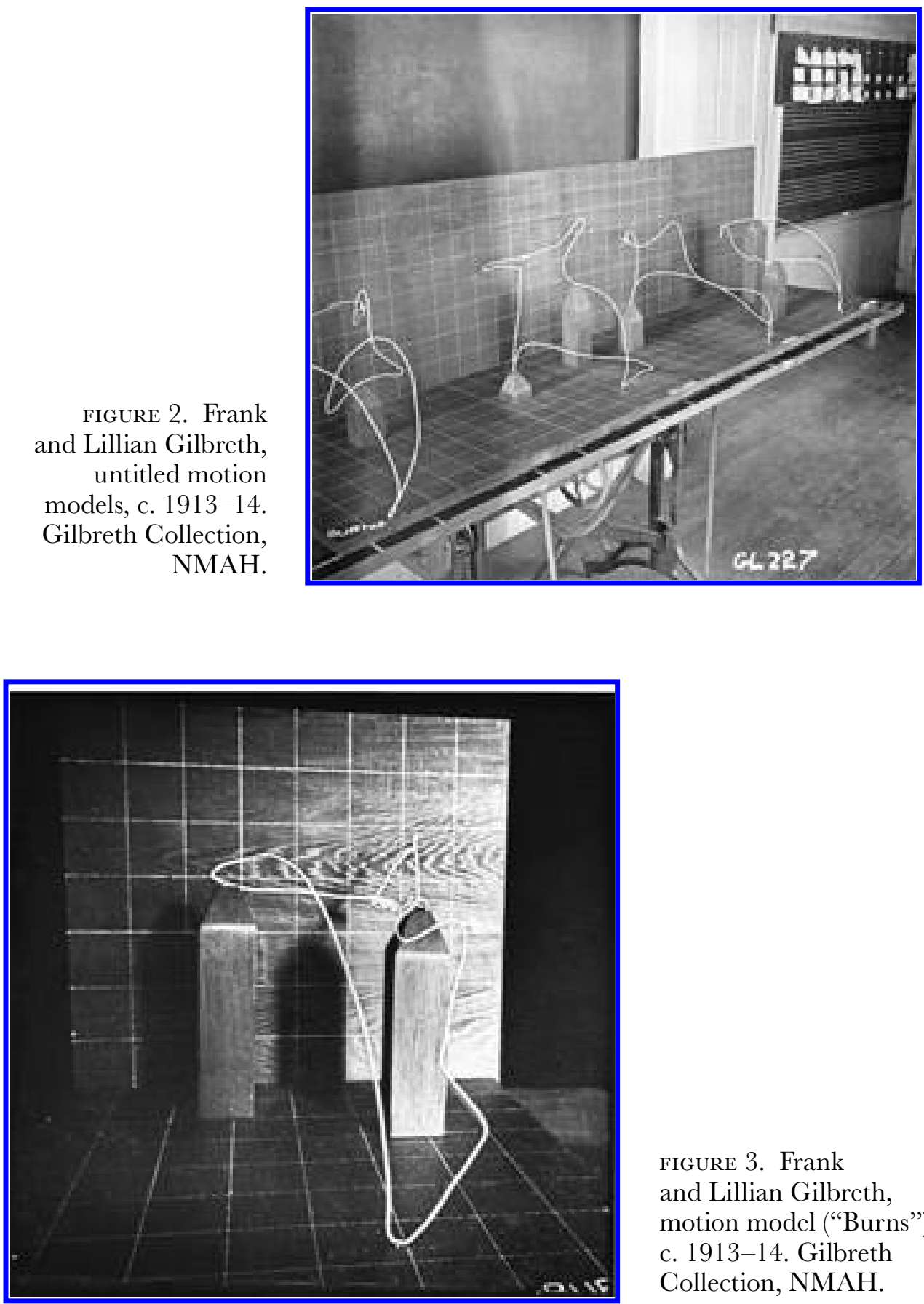

FIGURE 3. Frank and Lillian Gilbreth, motion model ("Burns"), c. 1913-14. Gilbreth Collection, NMAH. 
and pitch-black setting in which they are sometimes photographed (fig. 3). The graphic lines, symbolizing the workers' movements, render spatial movement by disembodying and aestheticizing it. (This sculptural effect is also apparent in the Gilbreths' use of stereography, which gives the cyclegraphs the illusion of threedimensionality when viewed through a stereoscope.) These rigorously simplified forms are not only fully abstracted from the worker who first produced the depicted motion but also wholly decontextualized from the production line itself - two points to which I shall return. It has even been suggested that the motion models were really little more than a public relations strategy - a way of advertising the claims and values promoted by the Gilbreths. ${ }^{26}$ They could function, in this sense, as portable props for the Gilbreths as they publicized their methods of efficiency engineering. The efficacy of the models as didactic tools seemed to matter less than their ability to represent - to visualize - the promises of scientific management.

The significance of the Gilbreths' practice, then, to my analysis of Precisionism is that it addressed and construed efficiency in visual terms. The Gilbreths used a number of mediums - the motion picture, the stereographic photograph, and the wire motion model - to give movement a visual expression; and in so doing, they had to address the question of what form efficiency should take visually. In the Gilbreths' system, a visual record of efficiency must collapse multiple lines into one unified line. That is, after all, what the wire motion model represents - an expression of motion as one simplified path. Inefficiency was thus seen as a tangle of "ragged" lines, to use Frank Gilbreth's description, that were the index of wasteful motion, while the simplified, and ultimately standardized, form was the embodiment of efficiency: the fewer lines, the less wasteful the motion. ${ }^{27}$ An illustration for the 5 June 1913 issue of American Machinist makes this comparison explicit (fig. 4).

Moreover, the visualization of efficiency in the Gilbreths' time-motion studies necessitated the erasure of the body of the worker and the standardization and abstraction of the act of labor. ${ }^{28}$ The time exposure of the film reduces the laboring body to a blur of motion - a mere ghost of itself - while the act of work registers photographically as lines of light (fig. 1). ${ }^{29}$ In some cases, the worker is completely elided, leaving only light traces abstracted against a blank background (fig. 5). The extent to which these studies were aesthetically conceived should not be underestimated. It seems that certain activities - fencing and golf, for instance - were chosen for motion study more for the spectacular light shows that they could provide than for some critical need of efficiency engineering. Also revealing is a piece of black paper in the Gilbreths' archive upon which the elongated dashes and lines of the chronocyclegraph are rendered in white paint. ${ }^{30}$ If this was not art for the Gilbreths, it certainly was close.

Once abstracted to white marks on a black background, the act of labor is fully detached from the worker; in this manner, the Gilbreths' motion studies offer a particularly vivid articulation of Karl Marx's notion of "alienated labor." For Marx, "alienated labor" refers not only to "the product of labor" that exists as an "alien 


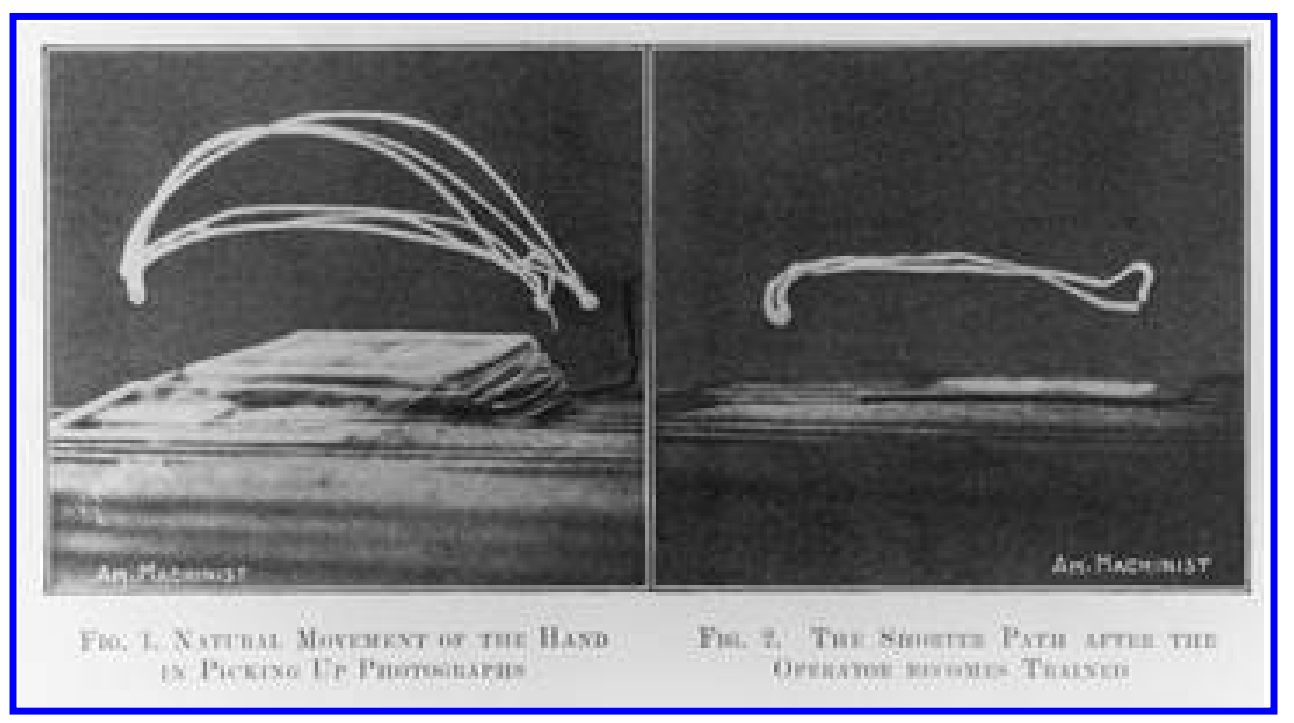

FIGURE 4. Frank and Lillian Gilbreth, untitled cyclegraph, 1913. Reproduced from American Machinist, 5 June 1913. Photo: Julie Wolf.

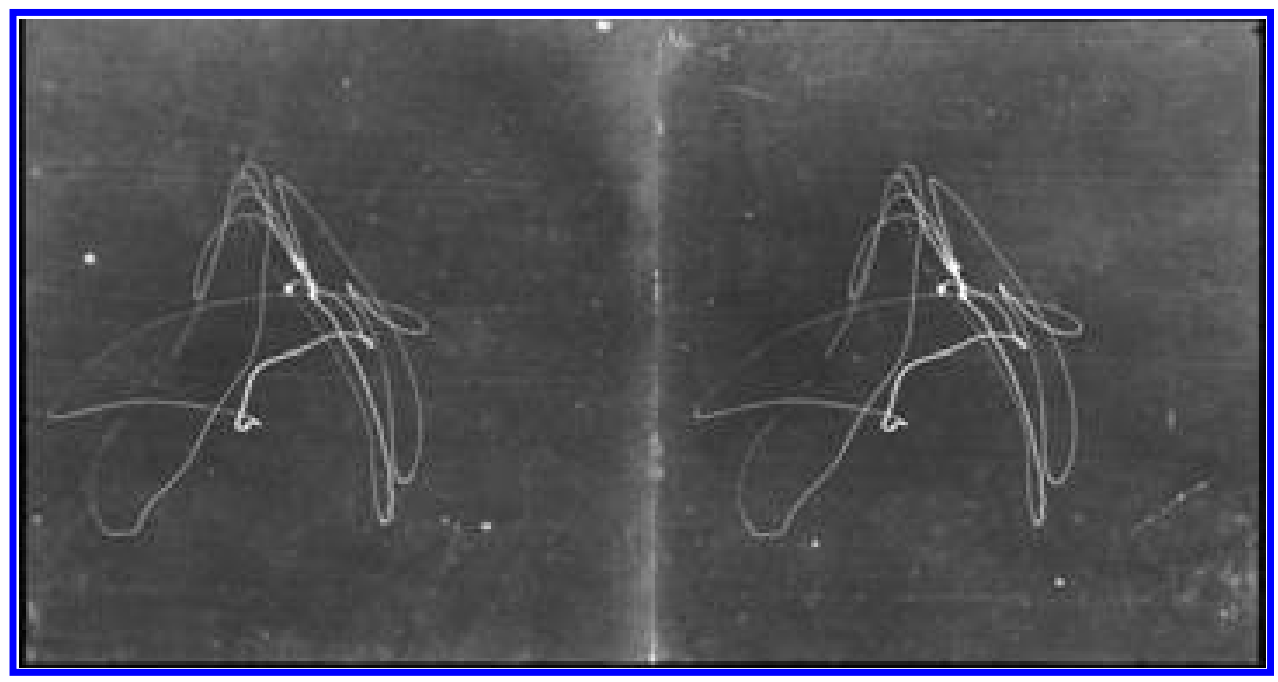

FIGURE 5. Frank and Lillian Gilbreth, untitled cyclegraph (fencing study), 1914. Gilbreth Collection, NMAH. 
object" to the worker but also to the act of labor itself, which becomes an object that exists "outside" and "independently" of the worker. ${ }^{31}$ To quote Marx on this point: "Alienation manifests itself not only in the result, but in the act of production, in the producing activity itself." 32 With the wire motion models, it can be said that the Gilbreths went even further in "alienating" the worker from his or her labor. The models function as abstract representations of labor in which the worker is wholly excised from the act of work, leaving only a reified trace of labor in its most efficient form. Remarkably, some of the models appear to be "signed": the names "Burns," "Allen," and "Lothrop" are visible in some photographs on the bases of certain models. These names, interestingly, do not refer to the individual whose motion is documented, but rather to the efficiency engineer who constructed the model. ${ }^{33}$ The elision of the laborer is thus twofold. The visualization of efficiency, it seems, necessitated the invisibility of the worker as the producer of labor.

Marx also argued that with the advent of factory labor, workers were involved in a labor process more profoundly socialized than ever before; he recognized the cooperation that workers maintained in order to keep production going:

In production, men enter into relations not only with nature. They produce only by cooperating in a certain way and mutually exchanging their activities. In order to produce, they enter into definite connections and relations with one another and only within these social connections and relations does their relation with nature, does production, take

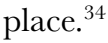

Yet within the Gilbreths' studies, images of such interdependent labor processes are rarely visible. Instead, the images present the ultimate Taylorist dream of work fully divided and surveilled. The visual effects of this fantasy - of labor made abstract and manageable - can be striking. In a cyclegraph (fig. 6), for example, the manager sits unmoving and thus fully delineated while the body of the worker - a laboring and hence moving subject - fades into near invisibility. The contrast between the corporeally intact manager and ghostlike presence of the worker offers a vivid representation of the systems of surveillance in place in the rationalized factory: only the manager, whose gaze is pointedly trained on the worker, is given the authority of vision. Importantly, the effacement of the laboring body is an effect of representational technology and has little or nothing to do with the messy improvisation and trial and error that characterize the real world of the production line.

The Gilbreths' studies, in this sense, exist in an idealized, illusory realm that sought to create its own visual vocabulary of efficiency - one in which labor is finally made fully alienated and therefore manageable through and through. Thus while the Gilbreths' project is fundamentally about visualizing the act of labor (to be distinguished from the subject of labor) - the messiness of that work is necessarily cleaned up, abstracted, standardized, and alienated. Precisionism also represents a certain kind of labor - one marked by an obsessive, even cultic adherence 


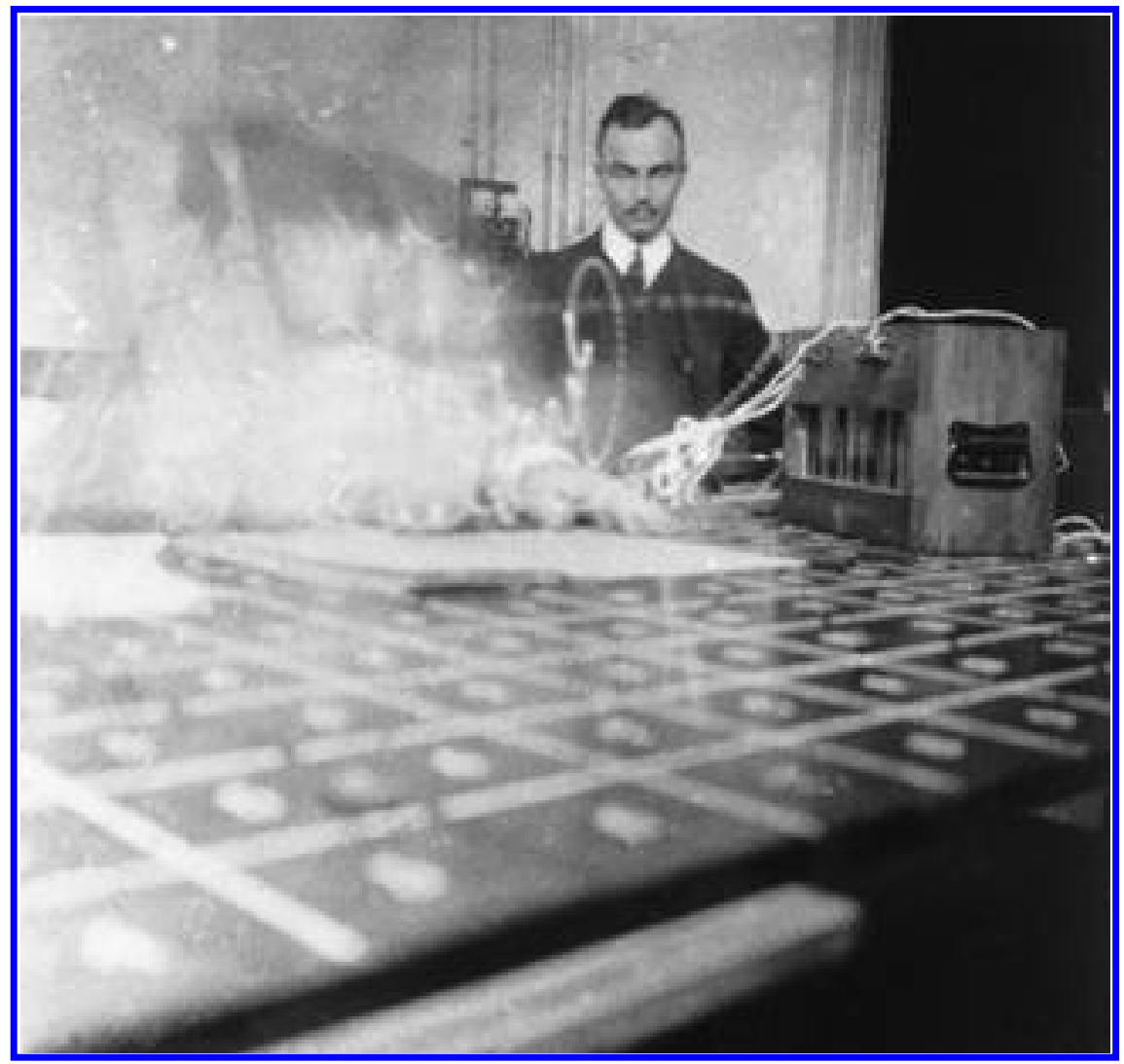

FIGURE 6. Frank and Lillian Gilbreth, untitled cyclegraph (office study), n.d. Gilbreth Collection, NMAH.

to a formal language of standardization and exactitude. My contention is that the Gilbreths and Precisionists were simultaneously concerned with making labor invisible - "alienating" labor, in other words, from both its maker and its product.

Turning to the visual culture of the day, Ford Motor Company's 1932 promotional film, Rhapsody in Steel, gives this fantasy of an abstracted, invisible labor force animated form (fig. 7). ${ }^{35}$ Shown in 1934 as part of Ford's participation in Chicago's Century of Progress Exposition, the film opens with various shots of the factory as workers and machines go about their respective duties. ${ }^{36}$ The second half of this twenty-two-minute film dramatizes the dream of autogenic production by depicting a V-8 automobile in the process of self-assembly. After the shop whistle blows to signal the end of the day's work, Ford workers are shown handing in their tools and departing the plant. Notably, the laborers in these scenes are only partially represented through metonymic signifiers of disembodied hands and legs. As they lay down their tools and walk out of the factory, these figures are seen not as individ- 


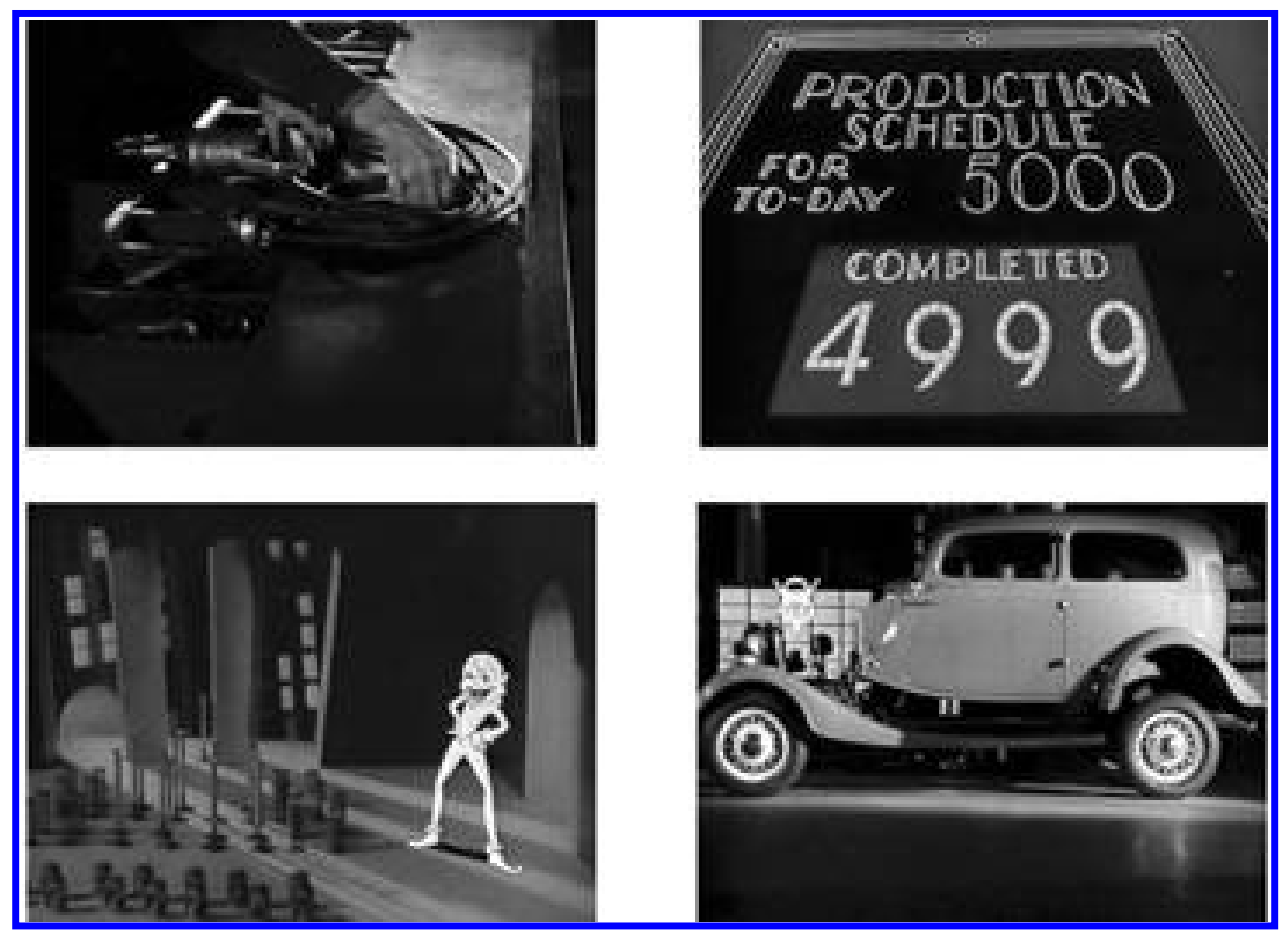

Figure 7. Ford Motor Company, stills from Rhapsody in Steel, 1932.

Ford Collection, National Archives, College Park, Md.

uals but as anonymous bodies. Once the workers have exited the scene, we are informed by a placard that they are one car short of the day's production schedule of five thousand cars. To remedy this shortfall, an animated figure morphs out of the V-8 symbol on the radiator grille of an automobile, looks disapprovingly at the production schedule that has not been met, and calls to attention various automobile parts including wheels, a cylinder block, and a chassis. Using stop-action animation, the film portrays these parts assembling themselves into a brand-new Ford automobile. It is not just the workers who are erased in this portion of the film; the factory itself is eliminated. The assembly of the V-8 instead takes place against the backdrop of a surrealistic city, far from the production line and its workers. The final half of the film thus enacts a fantasy scene in which human workers are entirely dispensable (at least when there is an animated imp to do the job) - both in the factory and in representation.

The fantasy of a machine (or painting) produced without labor is also made manifest in Morton Livingston Schamberg's 1916 "Mechanical Abstractions" (fig. 8) and Louis Lozowick's "Machine Ornaments" from 1922-27 (fig. 9). Schamberg 


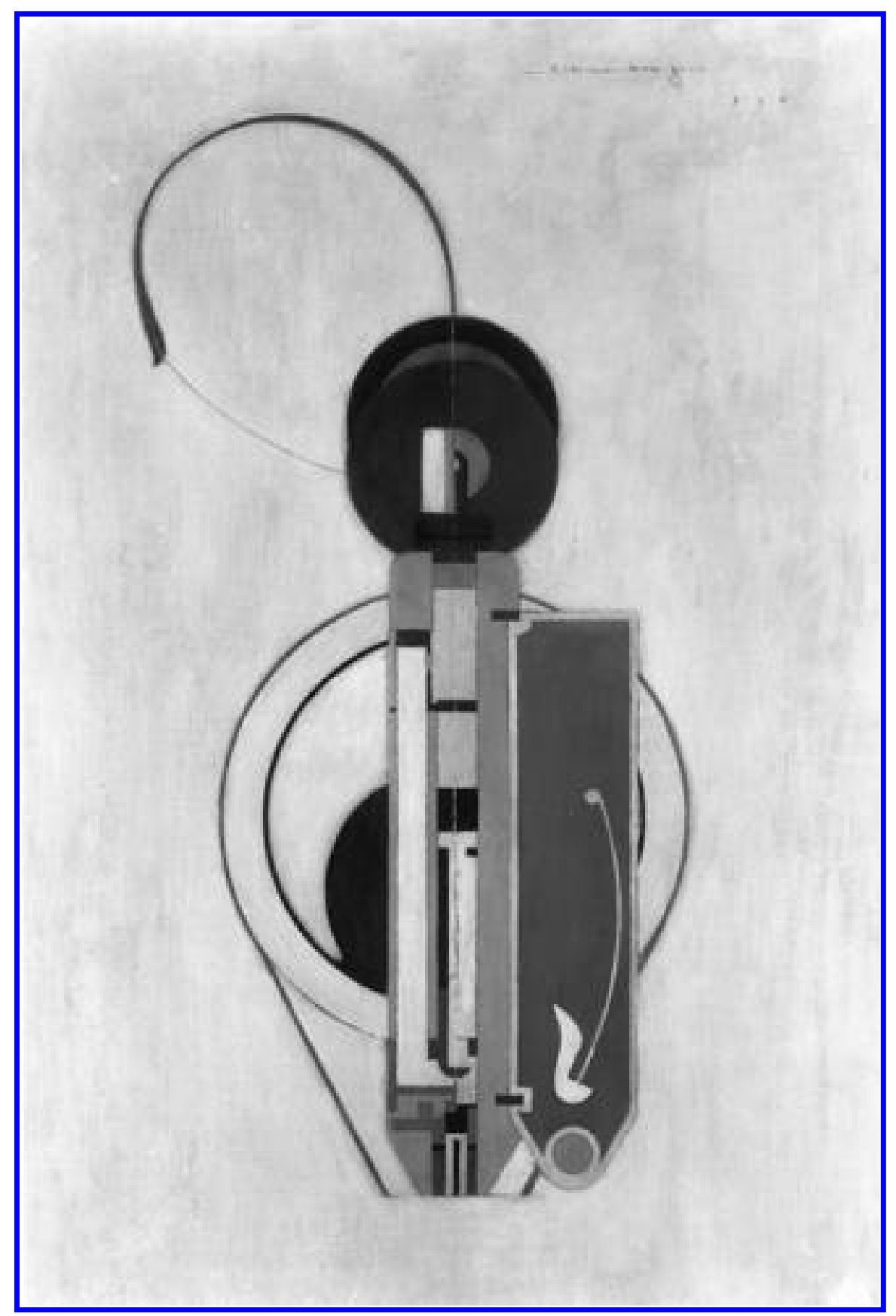

Figure 8. Morton Schamberg, Painting VIII (Mechanical Abstraction), 1916. Oil on canvas, $30^{1} / 8 \times 20^{1} / 4$ inches. Philadelphia Museum of Art: The Louise and Walter Arensberg Collection, 1950. 


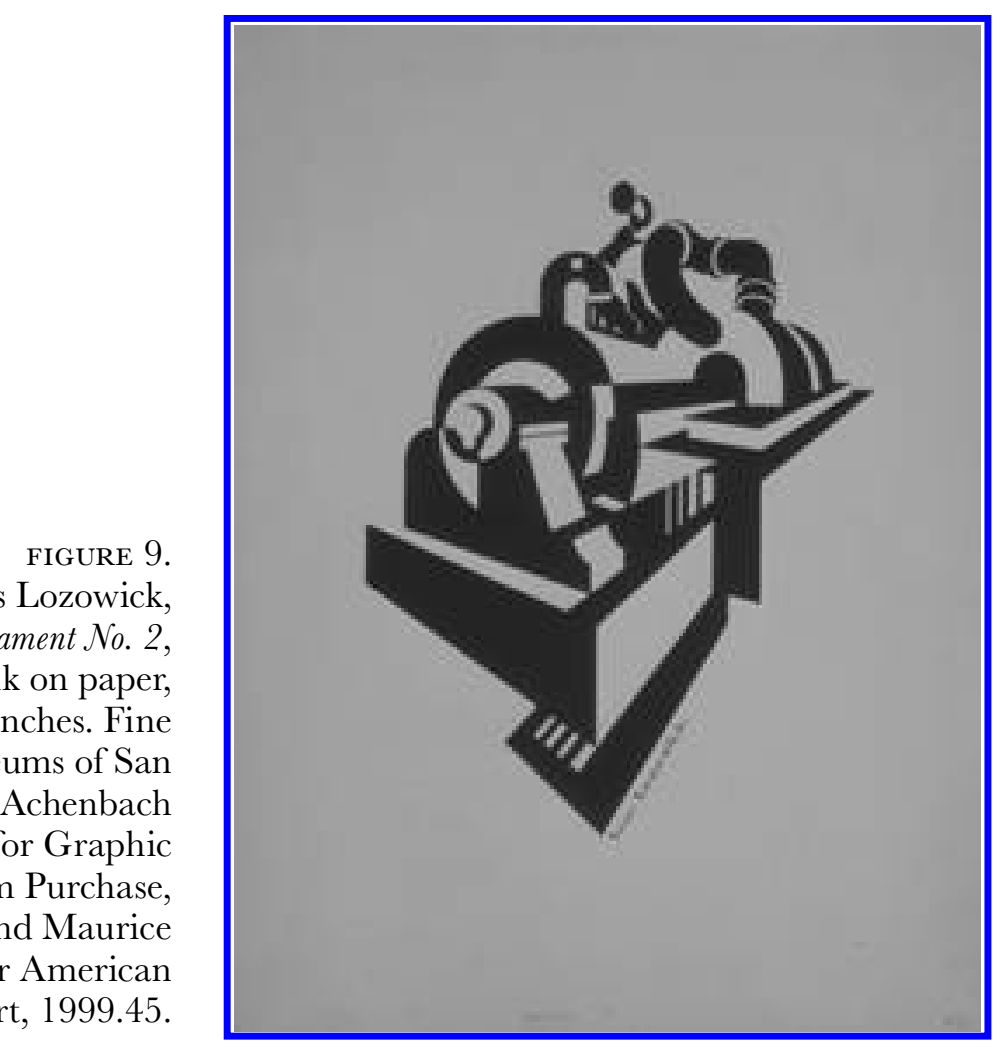

and Lozowick's machines not only conceal the artist's hand through the suppression of conspicuous brushwork; with their blank backgrounds, they also depict a machine wholly decontextualized from the factory as a site of labor. Lozowick's 1923 lithograph Cleveland (fig. 10), from his "Cities" series, also registers the qualities of efficiency, standardization, and economy that characterize scientific management through its repetition of smokestacks and silos and foreground of identical boxcars. With their linear forms and simplified stylistics, Precisionist works such as these not only represent the subjects of mass industrialism but also illustrate its values: the efficiency of the machine and the factory, in other words, is conveyed formally.

I am not, however, proposing an ideological equation between Precisionist art and industrial capitalism (although this is a claim that is all too often made). ${ }^{37} \mathrm{To}$ say that the formal project of Precisionism engages the rhetoric of the rationalized factory is not necessarily to say that its paintings function as a visual endorsement of this mode of production. On the contrary, I believe Precisionist art reveals a much more conflicted stance toward the status of labor - artistic as well as industrialin an age of increasing mechanization. Though Precisionist imagery was able, at times, to represent a vision of industrial America as an entity marked by progress and strength, this characterization can, I fear, blind one to the true strangeness and 


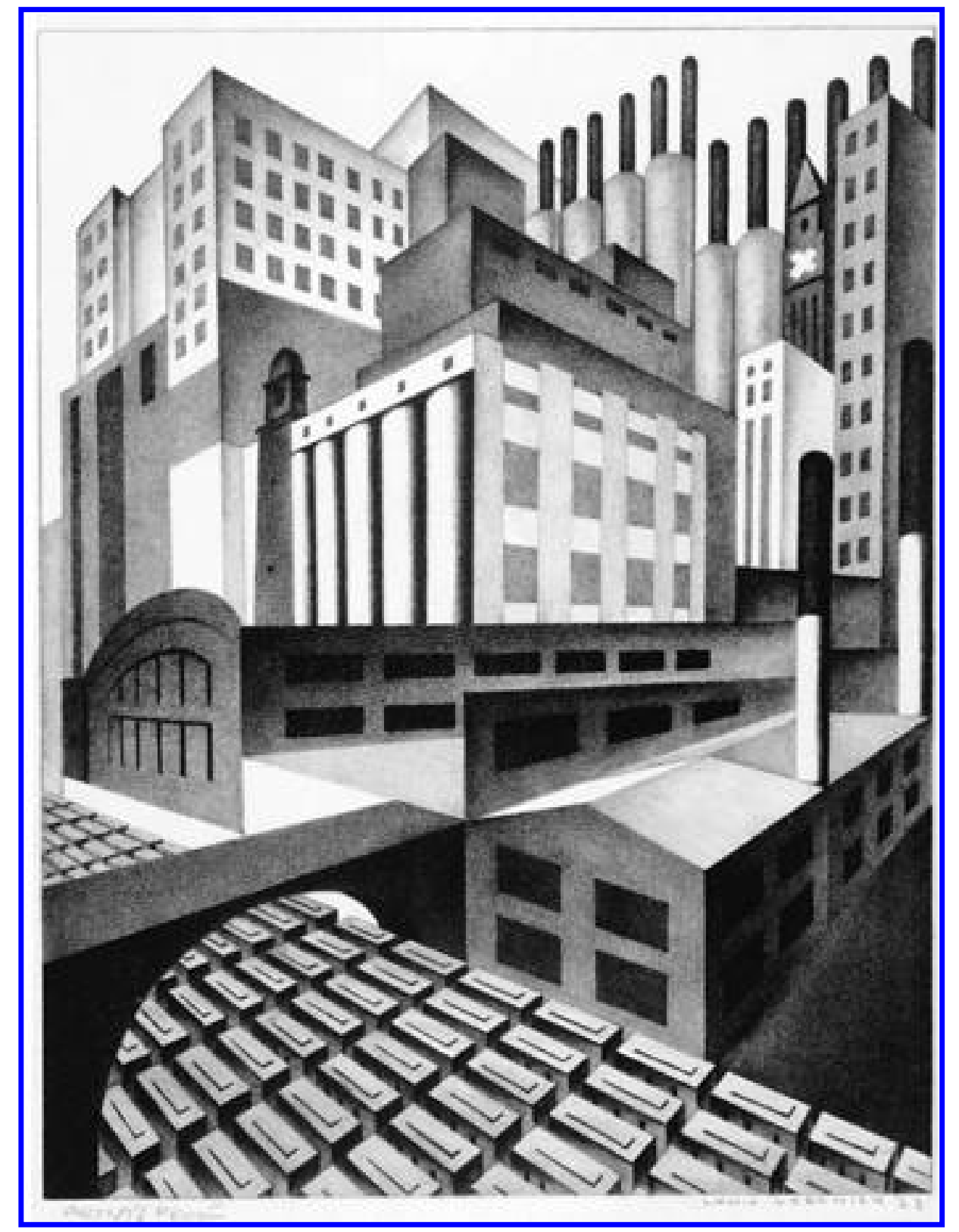

FIGURE 10. Louis Lozowick, Cleveland, 1923. Lithograph on paper, $11^{1 / 16} \times 8^{7} / 16$ inches. Smithsonian American Art Museum, Gift of Adele Lozowick. 
uncertainty of the Precisionist visual project. Precisionism can imagine an ideal modernity, but it does so through elisions and, perhaps more important, with tension and ambivalence. In particular, it is the obsessive - if not always successfuleffacement of artistic labor in Precisionist art that puts into doubt an untroubled confluence between art making and the forms and systems of modern life.

Precisionism's rhetoric of efficiency was, in part, grounded in the same desire to abstract or evacuate the body from the site of production that characterizes the Gilbreths' project. As I have shown, the workers in the Gilbreths' motion studies are often given only liminal status: laboring bodies are at times erased almost entirely from the scene. In other instances, workers are pictured with little regard for their corporeal integrity and are at times violently cropped by the picture frame (fig. 11). These eerily decapitated bodies resonate powerfully with Charles Sheeler's Self-Portrait (fig. 12) from 1923, in which the artist's reflection in the window is cropped just above his chin. In Sheeler's drawing, not only is the conventional iconography of self-portraiture withheld - no palette, no paintbrush, no canvas - but the artist himself is nearly absent. ${ }^{38}$ Sheeler's visage, in fact, is doubly concealed: first by the edge of the picture frame, and second by the dark band - a shadow about one-and-a-half inches wide cast by the window shade - that further obscures even the slightest hint of the artist's face. ${ }^{39}$ A close search for features beneath this shadow yields only frustration.

I can think of few self-portraits that are more self-effacing; the drawing offers little suggestion of Sheeler as the maker of this or any other artwork. ${ }^{40}$ Instead, the self-portrait presents a vision of selfhood clearly supplanted by the machine: the body of the artist is displaced by the telephone that sits firmly in front of his diaphanous torso, which is reflected in the window. The solidity of the one highlights the fragility of the other. Sheeler, in fact, seems quite willing to cede his corporeal density to this new prosthesis in a strangely masochistic depiction. Sheeler's original title for the piece, Still Life, serves to further obscure the portrait of the artist. ${ }^{41}$ This title (it was also called Nature Morte - Telephone) might additionally be read in relation to the inanimate quality of Sheeler's ghostly reflection. It is notable that early critics of the drawing seem not to have noticed the artist's portrait, or at least chose not to mention this figure in their reviews. ${ }^{42}$ The significance of the Self-Portrait, in the context of this discussion, is that it offers an early example of Sheeler's inclination toward artistic self-effacement - one that he would ultimately carry out through the suppression of his own visible labor in other works - and thereby speaks to Sheeler's deeply felt ambivalence in relation to the status of his artistic labor in a machine age. ${ }^{43}$

In the period under consideration, the products and systems of scientific management had to look efficient. Part of looking efficient - whether for an automobile or a painted canvas - meant obscuring (or alienating) the often messy, or at least painstaking, labor that went into the making of an object. To say that Precisionist 


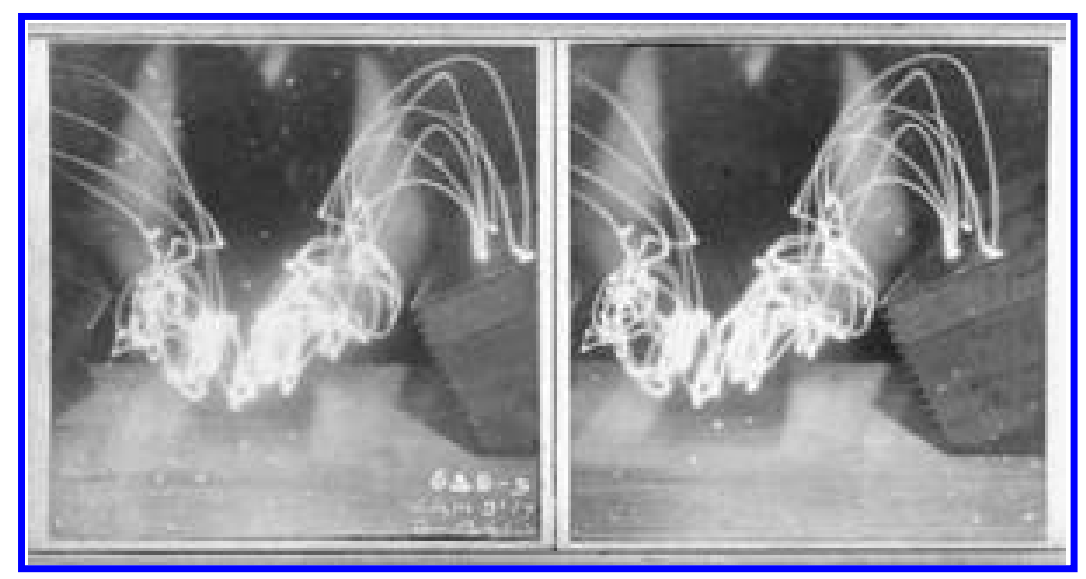

FIGURE 11. Frank and Lillian Gilbreth, untitled cyclegraph (assembly study), 1914. Gilbreth Collection.

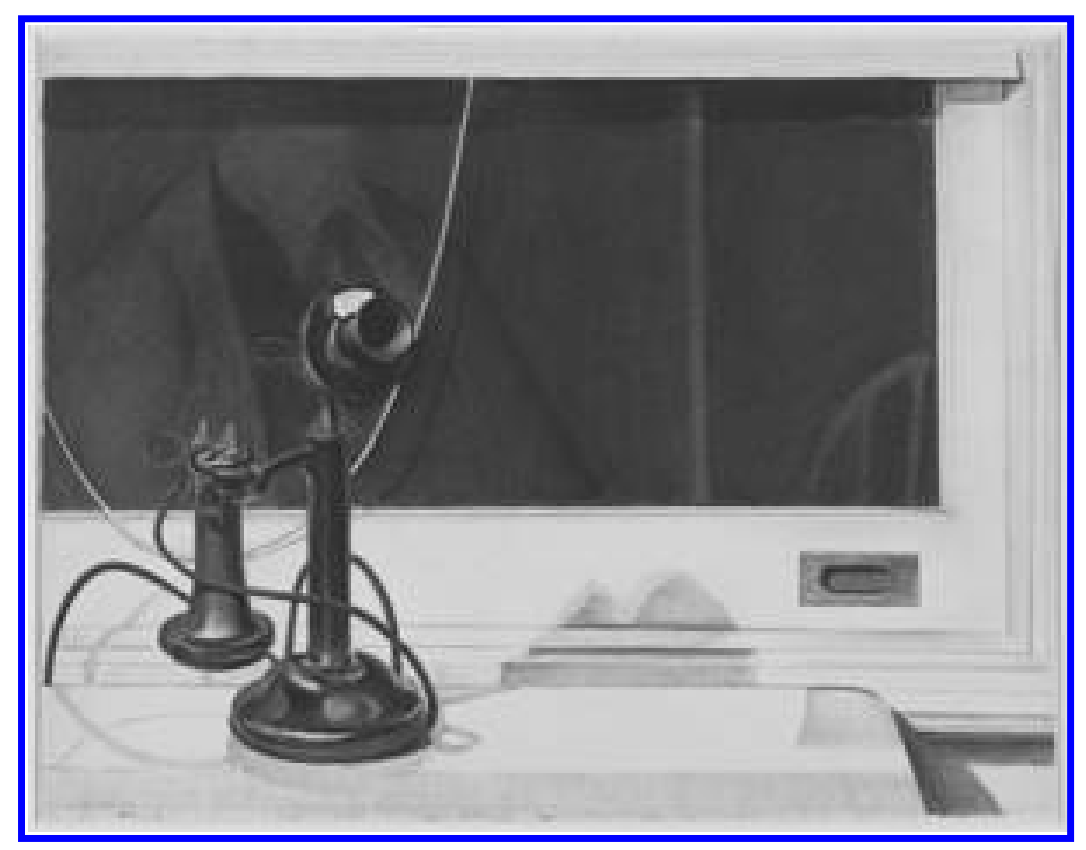

FIgure 12. Charles Sheeler, Self-Portrait, 1923. Conté crayon, gouache, and pencil on paper, $19^{3} / 4 \times 25^{5} / 8$ inches. Gift of Abby Aldrich Rockefeller (146.1935). The Museum of Modern Art, New York, N.Y. Digital image (C) The Museum of Modern Art/Licensed by SCALA/Art Resource, New York. 
artists were "alienated" from their labor is to point to the manner in which both the act of labor (the practice of painting) and the painting itself (the product of labor) might be seen to exist "independently" of the artists themselves. It is this tendency to disassociate the surface of the canvas from the means of its production or, in other words, to make labor invisible as a way of visualizing efficiency, that characterizes Precisionism. There is, in fact, very little on the surface of the Precisionist canvas to suggest the labor behind it: the indexical marks of making such as brushwork and underpainting are carefully concealed. This quality was recognized early on: in the mid-1930s, for example, the Index of Twentieth Century Artists describes the painting of the Precisionist Stefan Hirsch in the following manner: "There is never a trace of labor in his paintings and in the finished product every discordant element had disappeared." ${ }^{44}$ This assessment makes clear that labor was to be equated with discord; and in an age guided by the principles of order and efficiency, discord had to be effaced.

Sheeler was particularly interested in finding visual models of efficiency. "I speak in the tongue of my times," Sheeler noted in a 1938 article, "the mechanical, the industrial. Anything that works efficiently is beautiful. Barns and machinery are thus beautiful. ${ }^{{ }^{45}}$ Clearly, Sheeler was drawn to subjects that he associated with efficiency. The question that remains is how he developed an aesthetic of efficiency that could equal the precision, beauty, and production values of its representational subjects. One way Sheeler approached this task was to emphasize the linear qualities of his work - the rigorously simplified forms that make up his compositions as well as the subdued brushwork that characterize the surfaces of paintings such as the 1939 Rolling Power (fig. 13) - while at the same time disciplining painterly effects of impasto and dramatic chiaroscuro.

Like the Gilbreths, Sheeler desired to visualize efficiency as the absence of visible labor, and this goal fueled both his artistic efforts and his writings on art. He continually referred to his attempts to create an art that would betray none of his artistic labor. In the 1939 exhibition catalog to his one-person show at the Museum of Modern Art, the artist remarked, "In the days of the art school the degree of success in the employment of the slashing brushstroke was thought to be evidence of the success of the picture. Today it seems to me desirable to remove the method of painting as far as possible from being an obstacle in the way of consideration of the content of the picture." ${ }^{\prime 6}$ The paintings from his 1939 Power portfolio (of which Rolling Power is one of six) so successfully conceal the artist's hand that they were lambasted by one critic for having "nothing to offer beyond the colored photograph." ${ }^{47}$ Sheeler's work, in this regard, demonstrates the degree to which Precisionist painting is carried out through the suppression of the painter's individual mark. The painterly bravura that characterizes much modernist painting is wholly absent in the highly restrained surfaces of the Precisionist canvas. Indeed, brushwork was something that Sheeler attacked in his statements and eschewed in his art. In a 1952 interview, Sheeler lashed out at a Paul Cézanne still life: 


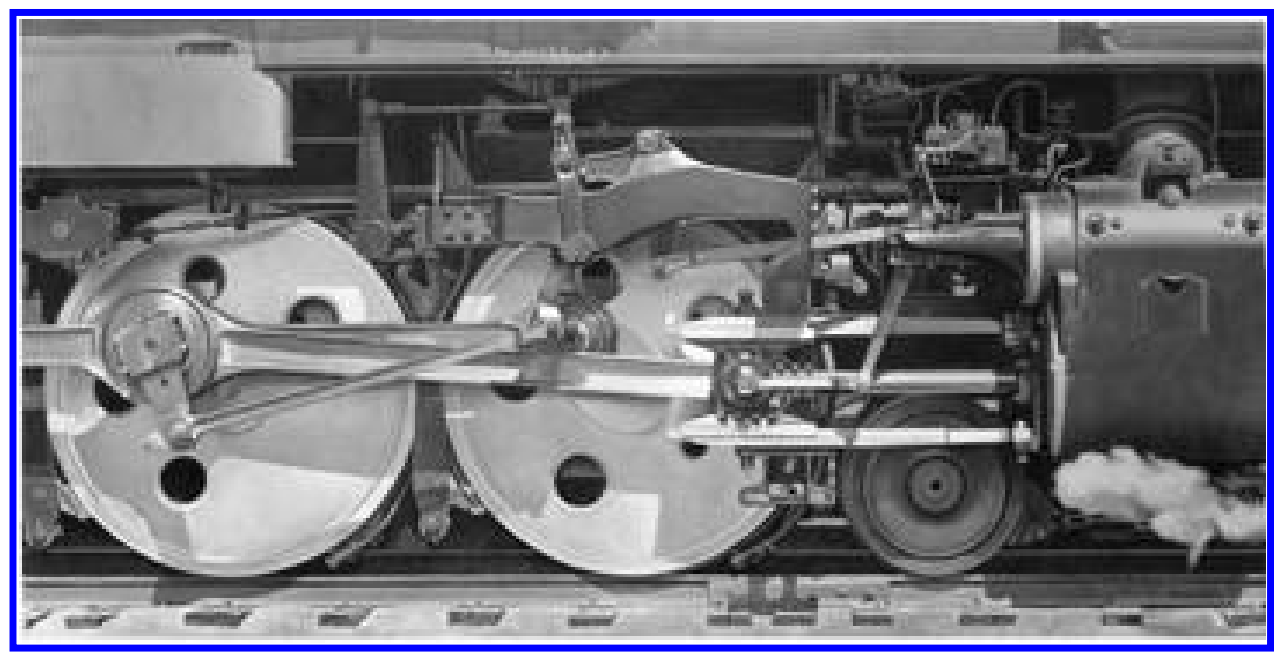

Figure 13. Charles Sheeler, Rolling Power, 1939. Oil on canvas, $15 \times 30$ inches. Smith College Museum of Art, Northampton, Massachusetts. Purchased, Drayton Hillyer Fund, 1940.

Well, you can almost hang your hat on some of those lumps of paint in those roses because he worked on them evidently for years. Nothing was removed of the underpainting, he just kept adding to it. Well, for me that is a hindrance to my integration with the picture. ... I just don't want to see any more than is absolutely necessary of the materials, physical material that goes into a picture. ${ }^{48}$

Sheeler's reading of Cézanne's surfaces is wildly overstated (one can only imagine what he might have had to say about van Gogh's facture). Yet his statement makes clear his resistance to such conspicuous (gratuitous might be Sheeler's characterization) displays of artistic labor, and his handling is clearly constructed to counter these terms: painted surfaces lie flat and brushwork is barely perceptible. Sheeler continually strove for efficiency as both image and practice in his art, and his Power paintings illustrate just how successful he could be in this pursuit-no line is wasted, no color is excessive, and no brushstroke is unaccounted for.

Sheeler's paintings thus appear as hyperrealist representations that with their seeming objectivity and verisimilitude obscure the elements of their artistic construction. By concealing his hand, Sheeler thought that he could arrive at a formula of painting that hid its labor in order to declare its efficiency. But it was only a formula, and in this sense, Sheeler's notion of efficiency differs from the goals espoused by Taylor and the Gilbreths. For the artist, of course, was under no pressure to perform the task of painting without waste of time or labor: it would have been ludicrous for him to consider time-motion studies appropriate to the act of placing paintbrush to canvas. Instead, Sheeler pursued efficiency as a uniquely visual effect. His objective was that the painting look efficient; that is, that it reveal none of the 
labor that went into its making. In other words, Sheeler was interested in creating an image of efficiency, not a more efficient way of painting. As he writes in his autobiographical notes:

I wanted to eliminate the evidence of painting as such and present the design with the least evidence of the means of accomplishment. ... For I favor the picture which arrives at its destination without the evidence of a trying journey rather than one which shows the marks of battle. An efficient army buries its dead. ${ }^{49}$

Sheeler's choice of words is striking: he seemed to envision his artistic project as a war of sorts - yet one in which no blood (or paint) is visibly shed. Critics at the time contributed to this reading of the occlusion of artistic labor upon the Precisionist canvases of Sheeler and his contemporaries. What is more, they viewed the effacement of artistic labor as a distinctly American trait. Stephen Bourgeois, a frequent exhibitor of Precisionist art at his Bourgeois Gallery, saw this connection when he wrote about Stefan Hirsch's work in a 1927 exhibition catalog:

Hirsch is, therefore, expressing an essentially American viewpoint, which he executes also in a characteristically American way - that is with a minimum of effort. His pictures seem to have been done without any effort. They have the perfection of something of which all effort has been eliminated previously to actual painting. And in this regard his work is of the greatest importance. ${ }^{50}$

According to Bourgeois, the American way is the most efficient way - the way, that is, of "minimum effort." Critics read Georgia O'Keeffe's canvases in a similar fashion. For Henry McBride, O’Keeffe's most successful painting miraculously seemed to manifest itself independently of the artist, the imagery appearing of its own accord. Singling out one of O'Keeffe's barn paintings, he wrote in 1933: "The artist seems to stand aside and let the barn do it all by itself. That's why I say the best O'Keeffes seem wished upon the canvas - the mechanics have been so successfully concealed." ${ }^{1}$ The critic may have been referring to O'Keeffe's canvas White Barn from the previous year (fig. 14). The artist's Canadian barns do, in fact, register the cool efficiency of industrialized manufacture. One might even say that O'Keeffe's barns appear to be mechanically assembled ("built" is how McBride described it earlier in his review) rather than painted-blue strip, joined to black trapezoid, constructed on top of white and black rectangles. ${ }^{52}$

Or as the critic Paul Rosenfeld put it in 1924, "Much of her work has the precision of the most finely machine-cut products. No painting is purer." ${ }^{53}$ Rosenfeld's invocation of machine manufacture in relation to O'Keeffe's aesthetic is significant to the analysis of labor that I have been outlining. "As the division of labor increases," Marx writes, "labor is simplified." 54 The marks of labor upon the products of mass production are thus subsequently elided, and the hand of the worker is eliminated. Purity, to use Rosenfeld's term, is thereby located in the visual language of the machine, not the worker. Furthermore, McBride's suggestion that 


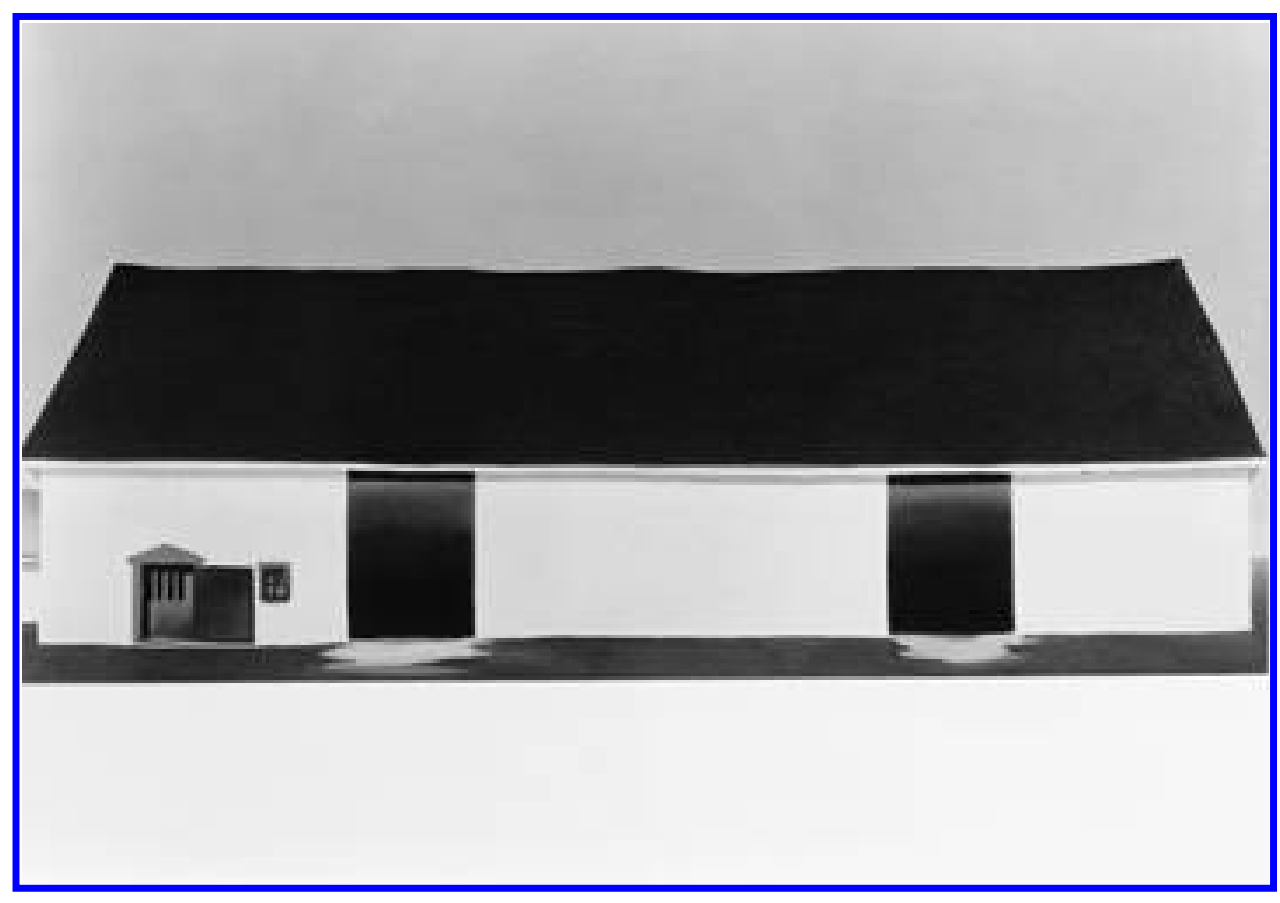

FIgure 14. Georgia O'Keeffe, White Barn, 1932. Oil on canvas, $16 \times 30$ inches. Collection of Mr. and Mrs. Paul Mellon.

O'Keeffe's best work seems "wished upon the canvas" serves to doubly "alienate" O'Keeffe as maker: in his account, she is essentially externalized from both the painting itself and the labor that went into its making. McBride was ultimately responding to the facture of the painting, which with its disembodied smoothness and economy gives the appearance of minimal effort. This visual effect, however, is the result of O'Keeffe's skilled labor - a labor that is exemplary precisely because it refuses to be seen.

The paradox of Precisionist art is, of course, that painting is a labor-intensive medium, all the more so when "precision" is the goal. Sheeler would generally spend seven to eight hours a day on a painting that might take up to nine months to complete. ${ }^{55}$ Paintings such as the 1929 Upper Deck (fig. 15) may well seem "wished" upon the canvas, but in actuality they were executed through careful planning and precise execution. Sheeler's reliance on photographic sources greatly enabled his efforts to predetermine the outcome of his canvases, and his paintings rarely deviate from the compositions provided by his source photographs (fig. 16). Sheeler's artistic efficiency is thus further apparent in his embrace of photography - arguably the most "efficient" medium in the visual arts. Unlike painting or drawing, which can appear overly labored, the photographic image registers very 


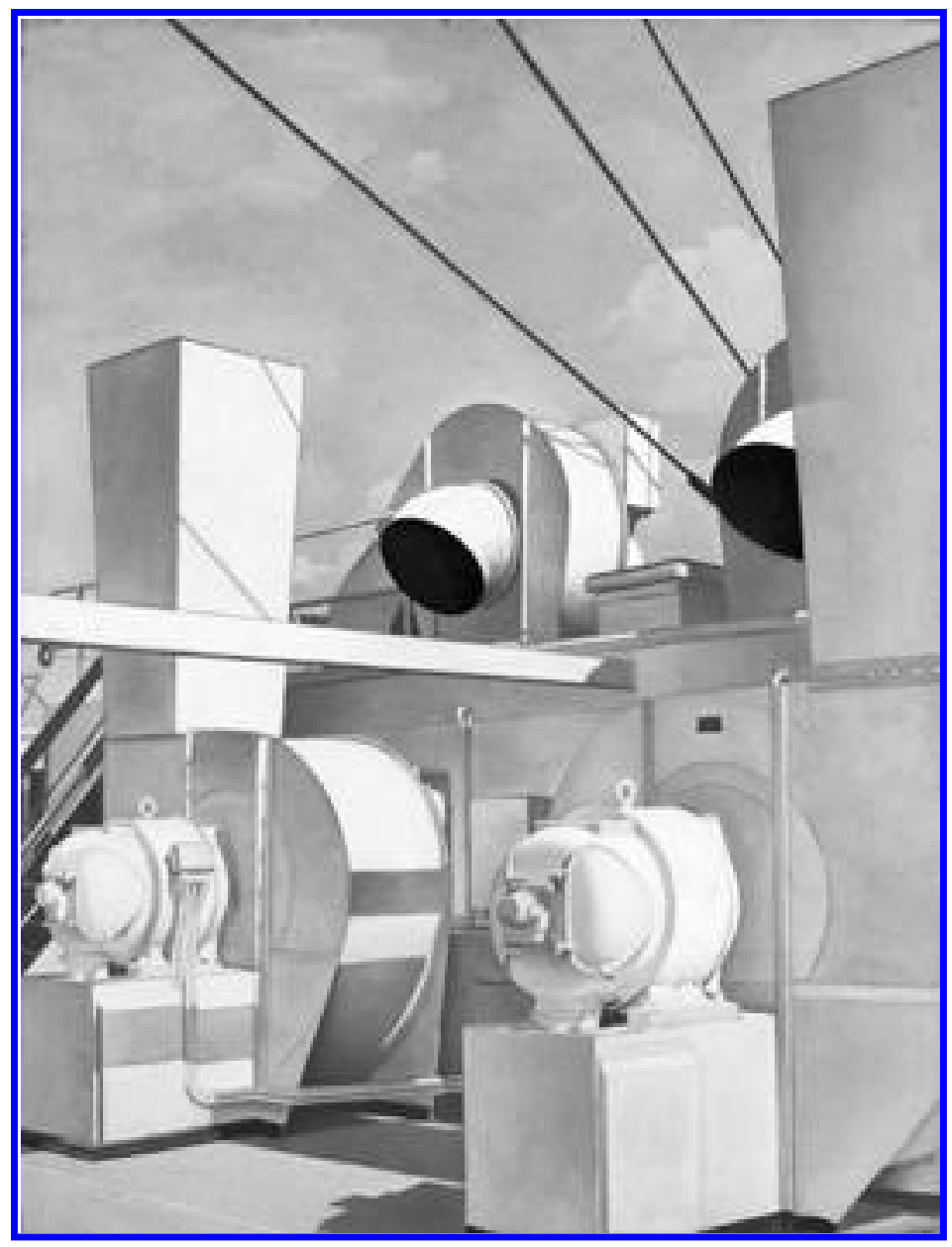

Figure 15. Charles Sheeler, Upper Deck, 1929. Oil on canvas, $29^{1} / 8 \times 22^{1} / 8$ inches. Harvard University Art Museums (Fogg Art Museum). Purchase, Louise E. Bettens Fund.

little of the work that went into its making. Yet photography, too, is full of waste and excess. Hundreds of photographs might be taken in order to achieve the one desired image, and the demands of the darkroom can themselves be laborious. It is this contradictory condition - the appearance of minimal effort despite often protracted labor - that tends to characterize efforts to visualize efficiency. Moreover, with its capacity for infinite reproducibility and exact duplication, the photograph participates in a language of standardization. The rhetoric of standardization was an integral part of efficiency discourse. Efficiency, as defined by Frank and 


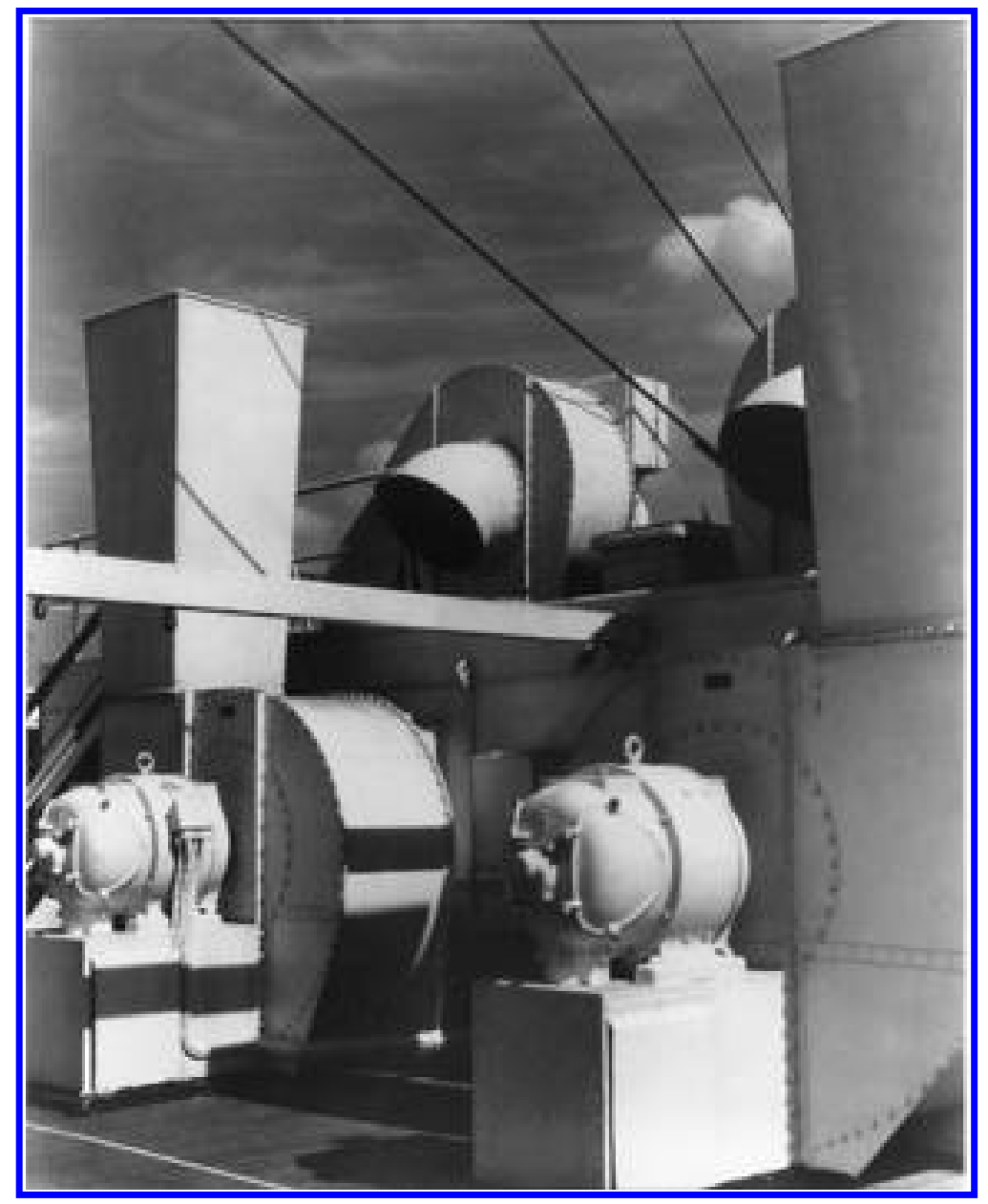

FIguRE 16. Charles Sheeler, Upper Deck, c. 1928. Gelatin silver print, $9^{1} / 2 \times 7^{5} / 8$ inches, Gilman Paper Company Collection.

Lillian Gilbreth, ultimately required standardization since it allowed tasks to be carried out without deviation from "the One Best Way."

Precisionist practice during the interwar years took up the rhetoric of mass production - at times adopting the mechanized medium of photography and working to conceal the marks of making on the painted canvas. These efforts resulted in a self-effacing style that obscures the artist's labor. For both Precisionist art and the Gilbreths' studies, the representation of labor - that of the artist and the worker - was somehow outside of the aesthetic of efficiency. Labor, in its abstracted, 
standardized, and ultimately efficient form, could be represented; yet the representation of artistic labor or the body of the worker was strictly circumscribed within a visual rhetoric of efficiency. In the end, looking efficient meant overlooking the visible traces of labor.

\section{Notes}

Michael Rogin's generosity, kindness, and wisdom have inspired not just this article but much of my thinking about American history and culture. I am forever indebted to his scholarship, teaching, and spirit. This essay is dedicated to his memory. An earlier version of this paper was presented as part of the "Art and Labor" session at the College Art Association Annual Conference in New York, February 2003. My thanks to the organizers, Stephen Eisenman and Andrew Hemingway, for the invitation to participate on the panel and for their insightful responses to my paper. I am also deeply grateful to Anne Wagner, Tim Clark, Sarah Kennel, Jessica May, Julianne Gilland, and Martin Kelly, all of whom helped to shape this essay in innumerable ways.

1. Frederick Winslow Taylor offers no reference for his citation of Theodore Roosevelt, yet a search of the president's papers reveals that Roosevelt mentions the importance of "national efficiency" three times in his "Special Message" of 22 January 1909 to the Senate and House of Representatives, in which he outlines the report of the National Conservation Commission; Theodore Roosevelt, "Special Message," 22 January 1909, in A Compilation of the Messages and Papers of the Presidents (New York, 1897-1922), 10:7640-41. This reference is consistent with the quote Taylor cites, which also mentions support for conservation efforts: "The conservation of our natural resources is only preliminary to the larger question of national efficiency . . . the larger question of increasing our national efficiency"; Theodore Roosevelt, quoted in Frederick Winslow Taylor, The Principles of Scientific Management (New York, 1967), 5.

2. Taylor, Principles of Scientific Management, 9.

3. Frank Gilbreth met Taylor in 1907 and quickly became a disciple of his methods, but by 1914 Taylor had begun to suspect that Gilbreth's motion studies strayed too far from his own principles of scientific management. When Taylor sent another of his followers to respond to a complaint issued by one of Gilbreth's clients, their relationship deteriorated beyond repair; see Samuel Harber, Efficiency and Uplift: Scientific Management in the Progressive Era, 1890-1920 (Chicago, 1964), 38; Daniel Nelson, Frederick W. Taylor and the Rise of Scientific Management (Madison, 1980), 131-35; Brian Price, "Frank and Lillian Gilbreth and the Motion Study Controversy, 1907-1930," in Daniel Nelson, ed., A Mental Revolution: Scientific Management Since Taylor (Columbus, Ohio., 1992), 58-63.

4. In one of his early publications, Gilbreth offers graphic illustrations of the "right way to pick up brick" and the "wrong way to pick up brick"; Frank B. Gilbreth, Motion Study: A Method for Increasing the Efficiency of the Workman (New York, 1911), 17-20.

5. Ibid., 88-89.

6. My research relies heavily on the Gilbreth Collection housed at the National Museum of American History (NMAH), Smithsonian Institution, Washington, D.C., and the Frank and Lillian Gilbreth Collection, Special Collections, Purdue University Libraries, West Lafayette, Ind. Many thanks to Peter Liebhold at the NMAH for his generous and knowledgeable assistance in working with the Smithsonian's Gilbreth archive. 
7. Robert Allerton Parker, "The Classical Vision of Charles Sheeler," International Studio 84 (May 1926): 72. Earlier in his review, Parker writes, "[Sheeler's] pictures suggest that fundamentally there is no antagonism between modern science and contemporary art" (69).

8. In a 1927 lecture at Bowdoin College, Alfred H. Barr Jr. issued what may have been the first use of the term "the Precisionists" in reference to Charles Sheeler and Charles Demuth. It was not until 1947, however, that the term "Precisionism" was used in connection with these artists and subsequently became the commonly used term for their art. Wolfgang Born first used this term in his Still-Life Painting in America (1947). He expanded upon his discussion of "Precisionism" one year later in American Landscape Painting: An Interpretation (1948); see Gail Stavitsky, "Chronology," in Precisionism in America, 1915-1941: Reordering Reality (Montclair, N.J., 1994), 155-56.

9. Theodore Roosevelt, "Special Message," 7641.

10. Harber, Efficiency and Uplift, ix.

11. See Richard H. Pells, Radical Visions and American Dreams: Culture and Social Thought in the Depression Years (New York, 1973), 71. The technocracy movement, which drew upon Thorstein Veblen's social and economic theories to solve the economic depression through the rationalized engineering of society, was similarly invested in the cult of efficiency. For more on Veblen and technocratic thought, see William E. Akin, Technocracy and the American Dream: The Technocrat Movement, 1900-1941 (Berkeley, 1977), 23-26.

12. Franklin D. Roosevelt, "Message to Congress Recommending Reorganization of the Executive Branch," 12 January 1937, Public Papers of the Presidents, F. D. Roosevelt, 1936, item 9.

13. Cecilia Tichi makes the claim that the efficiency movement had significant implications for the literary arts from this period. According to Tichi, Ezra Pound "advanced efficiency as a major criterion for all arts of the written word"; Cecilia Tichi, Shifting Gears: Technology, Literature, Culture in Modernist America (Chapel Hill, N.C., 1987), 90-91.

14. See Fred C. Kelly on Melville C. Dewey's campaign for simplified spelling in "Novel Ways of Saving Your Time, Labor, and Money," American Magazine 98 (September 1924): 24-35, 106.

15. See Harber, Efficiency and Uplift, 73.

16. Frank B. Gilbreth, "The Standardization of Spelling," The Society of Industrial Engineers Bulletin 5 (September 1923): 4.

17. Gilbreth, Motion Study, 99-100.

18. Typescript, n.d., Gilbreth Collection, Purdue University Libraries, N file, container 41, folder NAPTH/0261.

19. Motion study was defined by Gilbreth as follows: "The examination of the value, time, and sequence of motions for producing the greatest results in the least time with the least effort and fatigue"; Frank B. Gilbreth, Bricklaying System (New York, 1909), 312.

20. As Marta Braun argues, Gilbreth certainly would have known of Etienne-Jules Marey's earlier work in chronophotography; see Marta Braun, Picturing Time: The Works of Etienne-fules Marey, 1830-1904 (Chicago, 1992), 340-47. Yet Gilbreth seemed reluctant to fully acknowledge Marey's innovations as a generative source for his own methods. Begrudgingly, Gilbreth would write, "Marey is the man whom I wish had not been born. He got a cyclegraph. He set up a revolving disk with a hole in it before a camera, and he photographed this, and got a chrono-cyclegraph. We had to design a clock in order to photograph time in order to get a clock that would not jump. Marey's scheme was impractical, but he did the job, and he did it first"; Typescript, 5 October 
1914, Gilbreth Collection, Purdue University Libraries, N file, container 59, folder NAPTMC/0324-2A. Eadweard Muybridge's photographic motion studies also appear to have been influential for Gilbreth. Vicki Goldberg attributes Gilbreth's use of the grid to his familiarity with Muybridge's photographic motion studies, which also employed grids; see Vicki Goldberg, The Power of Photography: How Photographs Changed Our Lives (New York, 1991), 69.

21. Gilbreth began his cyclegraphs (motion studies) and chronocyclegraphs (time-motion studies) in 1913 while working at the New England Butt Company in Providence, Rhode Island, from 1912 to 1914. An early, if not the first, account of Gilbreth's revolutionary cyclegraphic and chronocyclegraphic methods at New England Butt is given in Fred H. Colvin, "The Latest Development in Motion Study," American Machinist 38 (5 June 1913): 937-39.

22. Frank B. and L. M. Gilbreth, Applied Motion Study: A Collection of Papers on the Efficient Method to Industrial Preparedness (New York, 1917), fig. 16.

23. Gilbreth's United States patent explains the function of the motion models as follows: "a wire is shaped to the true path of the proper movement, and is mounted in the proper position at the machine, or wherever the operation is to be performed. The workman then trains himself in the correct movements by following the wire with his fingers"; Frank B. Gilbreth, "Method and Apparatus for the Study and Correction of Motions," U.S. Patent 1,199,980, issued 3 October 1916. For more on the motion models, see Gilbreth and Gilbreth, Applied Motion Study, 97-130.

24. R. W. Allen in a letter dated 6 December 1915 to Frank B. Gilbreth; Gilbreth Collection, Purdue University Libraries, N file, container 151, folder NN2/0890. Allen is also quoted in Frank B. Gilbreth and Lillian M. Gilbreth, "The Effect of Motion Study upon the Workers," The Annals of the American Academy of Political and Social Science (May 1916): 3.

25. The only known surviving motion model is in the Gilbreth Library in the Industrial Engineering Department at Purdue University. I am grateful to James W. Barany for showing it to me. In person, this model is much less impressive than its depictions in the Gilbreths' photographs. Made out of painted plywood and what looks suspiciously like a bent wire hanger, the model is surprisingly fragile and diminutive.

26. Elspeth Brown discusses Gilbreth's use of photographic technologies as a public relations strategy; see Elspeth Brown, "The Corporate Eye: Photography and the Rationalization of American Culture, 1884-1929" (Ph.D. diss., Yale University, 2000), 58, 66, 88. Brown's book of the same title is forthcoming from Johns Hopkins University Press. Also see Richard Lindstrom, " "They all believe they are undiscovered Mary Pickfords': Workers, Photography, and Scientific Management," Technology and Culture 41 (October 2000): 733-37.

27. Typescript, 16 August 1915, Gilbreth Collection, Purdue University Libraries, N file, container 59, folder NAPTMC/0324-2A.

28. For more on the Gilbreths' efforts to standardize the movements of the worker, see Harry Braverman, Labor and Monopoly Capital: The Degradation of Work in the Twentieth Century (New York, 1974), 173-75.

29. Richard Lindstrom argues for the agency of workers in the Gilbreths' photographic studies. Workers, according to Lindstrom, participated in the construction of the images and at times were able to assert their own individuality through representation; see Lindstrom, " 'They all believe,"” 725-51.

30. It is possible that Frank Gilbreth painted the study. He was an avid whittler and seems to have shown some artistic interest, if not remarkable talent. The painted paper is 
found in the N file, container 59, folder NAPTMC/0324-2A, Gilbreth Collection, Purdue University Libraries. A box of Gilbreth's whittlings can be found in the Gilbreth Library in the Industrial Engineering Department at Purdue University.

31. Karl Marx, from the first manuscript of "Alienated Labour," in The Portable Karl Marx, ed. and trans. Eugene Kamenka (New York, 1983), 133-34.

32. Ibid., 136 (emphasis in original).

33. Burns, Allen, and Lothrop are addressed as efficiency experts throughout the transcript of the Gilbreths' third annual Summer School of Scientific Management held in Providence, Rhode Island, in August 1915; typescript, 18 August 1915, Gilbreth Collection, Purdue University Libraries, N file, container 59, folder NAPTMC/0324-2A.

34. Karl Marx, "Wage Labour and Capital" (1849), in Karl Marx, Frederick Engels: Collected Works, trans. Richard Dixon et al. (London, 1977), 9:211.

35. Rhapsody in Steel was directed by F. Lyle Goldmand with music by Edwin E. Ludig. A copy can be found in the Ford Collection, Motion Picture, Sound, and Video Recordings Division, National Archives and Records Administration, College Park, Maryland, item 4339. For more on Rhapsody in Steel, see William L. Bird Jr., "Better Living": Advertising, Media, and the New Vocabulary of Business Leadership, 1935-1955 (Evanston, Ill., 1999), 127-29.

36. The introduction of Henry Ford raises the question of what role Taylorism played in Ford's system of mass production. While Ford would claim that he developed his production methods independently from Taylor's system, historians have pointed out that Fordism ultimately adhered to the principles of Taylorism even if Ford may not have adopted the specific details of Taylor's scientific management. See David A. Hounshell, From the American System to Mass Production, 1800-1932: The Development of Manufacturing Technology in the United States (Baltimore, 1984), 249-53; Stephen Meyer III, The Five Dollar Day: Labor Management and Social Control in the Ford Motor Company, 1908-1921 (Albany, N.Y., 1981), 11, 14-21; Allan Nevins and Frank Ernest Hill, Ford, the Times, the Man, the Company (New York, 1955), 468-69. Whereas Taylorism was concerned with improving the efficiency of the worker, Fordism ultimately aimed at replacing the worker with the machine. For more on this distinction, see Hounshell, From the American System to Mass Production, 252.

37. See, for example, Terry Smith's treatment of Sheeler's paintings American Landscape (1930) and Classic Landscape (1931), which, he argues, "have come to symbolize American Industry triumphant" and, as he later claims, "picture an industrial America more conservative, restricted, and uninformative than Ford Company itself." Smith's reading ultimately turns on his assumption of Sheeler's "ideological consent" to the Fordist system; Terry Smith, Making the Modern: Industry, Art, and Design in America (Chicago, 1993), 116, 119, 126. Addressing the same paintings, Matthew Baigell calls Sheeler "the true artist of corporate capitalism"; Matthew Baigell, "American Art and National Identity: The 1920s," Arts Magazine 61 (February 1987): 51.

38. It has been suggested that the vertical stripe in the window may be a reflection of Sheeler's drawing board; see, for example, Susan Fillin Yeh, "Charles Sheeler's 1923 'SelfPortrait," Arts Magazine 52 (January 1978): 107. Even if this is the case, the reference to his artistic tools is subtle at best.

39. Sheeler's Self-Portrait would seem, in this sense, to blatantly refuse the "quality of interiority" that T.J. Clark identifies as one of self-portraiture's defining parameters: "A large part of self-portraiture's best efforts therefore go to conjuring up a dimension in which the surface of the face, and particularly the eyes, can register as something to be looked through and behind"; T.J. Clark, "Gross David with the Swoln Cheek: An Essay on 
Self-Portraiture," in Rediscovering History: Culture, Politics, and the Psyche, ed. Michael S. Roth (Stanford, 1994), 283.

40. Twenty years later Sheeler painted another enigmatic self-portrait, The Artist Looks at Nature (1943). Like his 1923 drawing, the painting confounds the traditional conventions of self-portraiture; it, too, addresses the theme of the artist's self-effacement. The painting, in fact, might be better described as a landscape since the majority of the image depicts a landscape setting - itself quite strange - with concrete walls and staircases amidst green lawns. At the bottom left of the painting, the artist is shown, back to the viewer, sitting at his easel with a pencil applied to his drawing. Yet the drawing that he is working on is neither a portrait of himself nor the landscape in which he sits. Instead, Sheeler is shown recreating a 1932 drawing, Interior with Stove, itself based on his c. 1917 photograph Doylestown House: Interior with Stove; see Karen Lucic, Charles Sheeler in Doylestown: American Modernism in the Pennsylvania Tradition (Allentown, Pa., 1997), 97-98; Carol Troyen and Erica E. Hirshler, Charles Sheeler: Paintings and Drawings (Boston, 1987), 183-84.

41. The drawing was first exhibited in November 1923 at the Durand Ruel Galleries in Paris under the title Nature Morte - Telephone. The first known use of the title Self-Portrait was in a letter from Edith Gregor Halpert, Sheeler's dealer, dated 16 April 1931; research notes by Olive Bragazzi, 15 April 1986, Museum of Modern Art curatorial files. Also see Troyen and Hirshler, Charles Sheeler, 96. The adoption of the new title, however, was relatively slow: in a 1932 review, the drawing was still referred to as "Still Life"; see Ernest Brace, "Charles Sheeler," Creative Art 11 (October 1932): 100. Constance Rourke notes the change of title in her 1938 biography of the artist; Constance Rourke, Charles Sheeler: Artist in the American Tradition (New York, 1969), 94.

42. Forbes Watson, for example, comments on "Mr. Sheeler's portrait of a telephone" with no reference to the portrait of the artist; Forbes Watson, "Opening the New Year," The Arts 5 (January 1924): 50. See also Ernest Brace's reference to Sheeler's "portrait of a telephone"; Brace, "Charles Sheeler," 104.

43. Karen Lucic is one of the few scholars to assert that Sheeler's artistic project displays profound ambivalence toward the machine age; see Karen Lucic, Charles Sheeler and the Cult of the Machine (Cambridge, 1991).

44. Index of Twentieth Century Artists: 1933-37 (New York, 1970), 375.

45. Charles Sheeler Papers, Archives of American Art, Washington, D.C., reel NSH1, frame 324.

46. Charles Sheeler, "A Brief Note on the Exhibition," in Charles Sheeler: Paintings, Drawings, Photographs (New York, 1939), 10.

47. Fortune magazine reproduced six paintings by Sheeler on the theme of "power" in its December 1940 issue; see "Power: A Portfolio by Charles Sheeler," Fortune 22 (December 1940): 71-84. Milton Brown, "Sheeler and Power," Parnassus 13 (January 1941): 46.

48. Charles Sheeler, transcript of an interview with Martin Friedman, 18 June 1952, Archives of American Art, 27.

49. Charles Sheeler Papers, Archives of American Art, reel NSH1, frame 172.

50. Stephen Bourgeois, A Catalogue of Paintings by Stefan Hirsch (New York, 1927); Stephen Bourgeois Papers, Archives of American Art.

51. Henry McBride, New Kork Sun, 14 January 1933; quoted in Mitchell A. Wilder, ed., Georgia O'Keeffe (Fort Worth, Tex., 1966), 17.

52. On the barn paintings, McBride writes, "The solidity of these edifices patiently built of tenderly pure pigment is something I do not understand"; ibid. Of course, this char- 
acterization of being "patiently built" would seem to contradict McBride's reading of these paintings as "wished upon the canvas." The point seems to be that artistic labor, no matter how "patiently" it might be rendered, could simultaneously (if paradoxically) be conceived in mechanized terms, thereby making it subject to the same demands as the modern factory (i.e., the pursuit of efficiency and the appearance of minimal waste). 53. Paul Rosenfeld, "Georgia O'Keeffe," in Port of New York: Essays on Fourteen American Moderns (New York, 1924), 203.

54. Marx, "Wage Labour and Capital," 225 (emphasis in original).

55. See Ann Whelan, "Barn Is a Thing of Beauty to Charles Sheeler, Artist," Bridgeport Post, 21 August 1939; in Downtown Gallery Papers, Archives of American Art, reel ND40, frame 502. 